\title{
Research competition with strings
}

Everyone agrees that support for New Zealand research needs reorganizing, but there is disagreement about the best way of going about it.

\section{Wellington}

NEw Zealand research is in a great tizzy. The Labour government of Mr Geoffrey Palmer is in the throes of radical reorganization of public support for research on the eve of an election (due on 26 October) which, according to the opinion polls, it is likely to lose. There is bipartisan support for the notion that there should be a reorganization, which has been much discussed in the past six years. But the research community fears that the new plans will plunge it from the frying-pan into the fire.

Many of the present anxieties came to the fore at last week's annual meeting of New Zealand chemical societies at which, at one stage, Mrs Margaret Austin, the Minister of Research, Science and Technology, and the opposition spokesman (for the National party), $\mathrm{Mr}$ Simon Upton, indulged in the somewhat unconstitutional exercise of commenting on an explanation of the reformed structure offered by her chief executive, Dr Basil Walker. But it remains far from clear what the outcome of the reorganization will be even if the present government wins October's election.

One objective of the reorganization is transparency, which is generally applauded; the government will declare publicly its objectives in research, and will then arrange that the funds available from the public purse will be allocated so as to achieve them. For that purpose, there is (since last December) a Foundation for Research, Science and Technology established as a statutory agency reporting to the minister, but responsible to the New Zealand parliament.

The foundation will eventually allocate the whole public subvention of civil research (estimated to be NZ\$292 million in the financial year from 1 April) to appropriate 'research providers'. The ministry, on the other hand, will be responsible for providing the government as a whole with advice on scientific developments as well as for the definition of research objectives, which Austin promises will be a wide consultative process. (Walker wishes there were more time for the definition of objectives for 1991-92, which must be completed by November.) There is also a cabinet committee (under Austin) for coordinating policy between various ministries.

For researchers, there are several sources of confusion, of which the chief is the language in which the new policy for research is couched. Research organizations are renamed "providers", the product of research is "output", its cost is "input" and the criterion by which funds will be allocated is known as "contestability". Walker last week, while apologizing for the "economics-based" language, did little to clarify what is meant by "contestability": it is "principally about enhancing and improving the relevance and quality of science in New Zealand... focusing on the needs of our society . . promoting a greater awareness of the necessity of making the very best use of limited resources". That sounds like competition for funds within a predefined framework of objectives. But Walker was at pains to emphasize that the new foundation will have, at any time, a "portfolio" of research investments ranging from shortterm applied projects to longer-term (perhaps ten-year) projects as well as projects in basic research where, outputs and inputs would be virtually indistinguishable.

A further difficulty is that New Zealand's seven universities are, for the time being, excluded from the pool for the support of "public good research". Indeed the government is now in the thick of negotiation with vice-chancellors on the conditions under which they would be able to compete for (or "contest") funds available from the pool. It seems reluctantly to have been agreed by the universities that they will have to sacrifice some of their recent support in return for access to a research pool augmented by their own contribution to it. The question is simply how much they should give up. The universities have offered NZ\$5 million, but the government is asking for NZ\$20 million. One university vice-chancellor says that that would cost the universities 400 jobs, about 5 per cent of the total.

Much will hang on how priorities are defined. One danger is that the process of consultation will match the priorities to the present pattern of research, with the result that research organizations will extrapolate their present activities into the future. Among academic researchers, there is great resentment that they have traditionally been disadvantaged, in equipment and research support, compared with researchers at the Department of Scientific and Industrial Research (DSIR), the chief government research agency. But DSIR has already been required to give up "near-market research", seeking support for that from industry rather than from government. (The chemistry division boasts that it now receives NZ\$22 million from the government and NZ\$14 million from other sources.) Even if the research priorities reflect the status quo accurately, there will be fewer crumbs from DSIR's table to sweep in the direction of academics.

Perhaps a greater danger is that priorities will be too fashionably determined. Hitherto, much government support for research has been directed towards the needs of primary industries such as agriculture, forestry and fisheries. The 50strong New Zealand Wool Research Organization has, for example, an international standing in its field. Many of these organizations are alarmed that the near-market doctrine and the practice of "contestability" will see a further shrinkage of the proportion of their support that comes from public funds, in most cases already far below the 50 per cent offered when they were established. The risk of that happening will be all the greater if the priority-setting process pays scant attention to the primary industries.

But the poor cousins in the new arrangements, as in the past, are likely to be academic researchers. Not to join the pool will be a recipe for short commons, but to join it may imply that the pattern of academic research will be externally decided. Matters are made even worse by the general economic pressure to which the universities are now subjected. For the first time, undergraduates now pay tuition fees (NZ\$1,200 a year). Research funds out of general university income are sparse - NZ\$1,500 a year for each of a department's $\mathrm{PhD}$ students seems quite general. Academics' own access to research funds often depends on collaboration with better heeled partners, perhaps those in government laboratories. But there is a general fear that contestability will mean that research partners are less generous than in the past.

The most curious feature of the reorganization is that it is so self-contained. While the policy-makers insist that a small country (with a population less than that of Scotland) cannot do everything, little attention has as yet been given to collaboration on research projects with partners elsewhere as a means of lessening the risks of bad choices - and of alienating those whose research interests lie outside its current priority-set.

John Maddox 